\title{
Methodological development of a specific tool for assessing acceptability of assistive systems of powered two-wheeler-riders
}

\author{
Elisabeth Füssl' ${ }^{1}$, Manuel Oberlader1, Vanessa Beanland², loanna Spyropoulou ${ }^{3}$, \\ Michael G. Lenné4, Somya Joshi ${ }^{5}$, Lars Rößger ${ }^{6}$, Lars Leden7, Geoff Underwood, \\ Jose Carvalhais ${ }^{9}$ \\ ${ }^{1}$ Factum OG, Danhausergasse 6/4, 1040 Vienna, Austria \\ ${ }^{2}$ Research School of Psychology, The Australian National University, Canberra, Australia \\ ${ }^{3}$ National Technical University of Athens, Greece \\ ${ }^{4}$ Accident Research Centre, Monash University, Clayton, Victoria, Australia \\ ${ }^{5}$ Department of Computer and Systems Sciences (DSV), Stockholm University, Sweden \\ ${ }^{6}$ Technical University Dresden, Germany \\ ${ }^{7}$ VTT, Finland and Luleå University of Technology, Sweden \\ ${ }^{8}$ University of Nottingham, United Kingdom \\ ${ }^{9}$ Faculty of Human Kinetics, Universidade de Lisboa, Portugal \\ E-mail: elisabeth.fuessl@factum.at
}

\begin{abstract}
Research on the acceptability of assistive systems for improving the safety of powered two-wheelers (PTWs) is a pressing issue. The use of safety-enhancing assistive systems for motorised vehicles, including advanced driver assistance systems and in-vehicle information systems is widespread in many countries. Yet, there is only a limited number of equivalent intelligent transport systems (ITS) for PTWs, namely advanced rider assistance systems and on-bike information systems. This study describes the methodological development of a specific tool for assessing motorcyclists' acceptability of ITS, as part of the motorcyclists' profiling questionnaire (MOPROQ). There were three stages of development. First, a literature review was undertaken to assess the current state of the art regarding ITS for PTWs and to determine the most relevant facets of acceptability that should be measured. Second, a series of focus group interviews were conducted to explore riders' attitudes towards ITS. Finally, the focus group results were used to develop a large-scale survey (MOPROQ), which was administered to an initial sample of over 6000 riders internationally. The designed tool can be used as a basis for the determination of rider acceptability of ITS systems in the future.
\end{abstract}

\section{Introduction}

Powered two-wheelers (PTWs; i.e. motorcycles and mopeds) comprise a vulnerable road user group as they exhibit substantially high injury risk and severity rates especially when compared with other road users and in particular passenger cars [1]. Several measures have been proposed or implemented to reduce PTW risk and severity rates [2]; one such category attracting increasing attention in the road safety community is intelligent transport systems (ITS). ITS and other assistive systems have been shown to have considerable road safety benefits for passenger cars [3, 4]. Estimates suggest that population-wide deployment of advanced rider assistance systems (ARAS) could reduce crashes by up to $40 \%$ [5]. Still, there has been limited development of ARAS and on-bike information systems (OBIS) for PTWs.

The successful deployment of assistive systems is dependent on several variables, which are correlated, including system operating characteristics, user behaviour and attitudes towards the systems. Safety systems can only successfully reduce the incidence and severity of road crashes if the technologies are perceived as both effective and beneficial to the intended user group. Hence, rider acceptability is a crucial prerequisite for the successful implementation of a system, since if riders do not accept the system they will not use it [6]. To increase system acceptability, it is of significant importance to understand the barriers that may prevent motorcycle riders from accepting and properly using ARAS and OBIS.

There has been a limited amount of research exploring riders' acceptability of assistive systems. This research has focused on a narrow range of systems, with intelligent speed adaptation (ISA) receiving the greatest attention, for example [7-9]. Previous acceptability research has used focus groups or small-scale trials (e.g. 10 riders) to explore riders' attitudes towards ITS and safety systems, resulting in small sample sizes. Although such methods are useful for 
obtaining an initial impression of the community's opinion, the small sample sizes limit the representativeness and generalisability of conclusions. The aim of the current study was therefore to develop a new survey tool, which can be used to assess acceptability of a diverse range of assistive systems among a large sample of riders.

In the following section issues concerning ARAS and OBIS and system acceptability are discussed. Section 3 then outlines the methodology leading to the definition of part 3 of the motorcyclists' profiling questionnaire (MOPROQ-3), which is used in a quantitative survey that assesses riders' acceptability of assistive systems. Further, this section presents the findings of the focus group interviews that formed the basis of MOPROQ-3, and presents initial results from a wide-scale, international web-based administration of MOPROQ.

An overall conclusion on the methodology and benefits of MOPROQ-3, as well as future research perspectives are provided in Section 4.

\section{ARAS and OBIS}

The necessary background knowledge for developing the MOPROQ-3 tool was amassed through an initial review of literature in two domains: the current state-of-the-art in terms of PTW assistive systems, and models of acceptability. The key findings from this review are summarised in the following two subsections.

\subsection{Current state-of-the-art against crash types}

There are only a few ARAS that are currently commercially available; most systems are still at the experimental or developmental stage. Examples of systems at an experimental stage include intersection support [10], intelligent curve warning system [11], lane keeping and lane changing support $[12,13]$, collision warning system [13] and autonomous braking [14, 15].

Currently the most widely-used form of ARAS are anti-lock braking systems (ABS), which have long been available for both PTWs and four-wheeled vehicles. Incorrect braking of motorcyclists has been identified as a contributing variable in many motorcycle accidents [16, 17]. The benefits of motorcycle $\mathrm{ABS}$ in terms of crash reduction and mitigation of crash outcomes have been demonstrated in several studies [17-19]. In a provisional agreement reached between the European Parliament and Council of Ministers in September 2012, it was decided to make ABS mandatory by 2016 for all motorcycles with more than $125 \mathrm{cc}$ displacement [1].

Compared with driving, riding a PTW involves much greater risk as riders face a number of risk variables that do not affect passenger car drivers, the most important of which are vulnerability, conspicuity and environmental hazards. The Motorcycle Accidents In-Depth Study (MAIDS) [16] provides an overview of the main accident contributing variables, which are human error $(88 \%)$ and environmental related hazards $(8 \%)$. PTW riders are described as vulnerable road users because of their relative lack of protection against impacts with other vehicles, roadside objects and the ground [20]. PTWs have decreased stability at high speed and a much lower level of occupant protection compared with car drivers or passengers [20, 21]. Riding speed is positively correlated with the risk of being involved in a crash, as well as injury risk and injury severity in the event of a crash [22, 23]. Moreover, PTW riders often sustain multiple injuries. Head injuries, thorax injuries and cervical spine injuries more often have fatal consequences for PTW riders than upper and lower extremity injuries [24].

The most frequent type of human error $(50 \%)$ involved in PTW crashes is another road user's failure to see the PTW within the traffic environment, because of lack of driver attention, temporary view obstructions or the low visual conspicuity of the PTW [16]. In terms of conspicuity, PTWs are low on both sensory conspicuity and cognitive conspicuity [25]. Low sensory conspicuity means that PTWs are less visible to other road users because of smaller vehicle size (relative to four-wheeled vehicles) and often dark colours, concerning both motorcycles and motorcycle riders' clothes [26]. PTWs have low cognitive conspicuity because they are often incongruent with drivers' expectations: other vehicle drivers expect that most traffic will be passenger cars, since PTWs account for only $1-2 \%$ of motorised traffic in many developed countries [27]. Moreover, they expect vehicles to appear in designated lanes whereas PTWs can violate this expectation by appearing between lanes as they frequently exhibit movement that involves lane splitting and filtering [7]. Roadway maintenance defects and environmental hazards have greater significance for riders than for car drivers [21]. Environmental hazards account for around $8 \%$ of PTW accidents [16]. Assistive systems therefore might offer support for PTW riders in specific situations, especially where the operation of the systems addresses the aforementioned particularities of PTWs.

Based on the established facts about risk variables for PTW riders and ITS that were mentioned within the focus group discussions, a list was compiled of ARAS and OBIS that have the potential to reduce crash risk or mitigate crash consequences (see Table 1).

\subsection{Acceptability}

In contrast to infrastructure based ITS, consumers have substantial choices when deciding which in-vehicle or on-board ITS to use. It can be assumed that only those systems which are perceived as being useful for the customer will be purchased or retrofitted [6]. Furthermore, systems are only likely to have a positive effect on accident risk and driver behaviour if they are accepted and used properly by the vehicle operator. Hence, rider acceptability is a prerequisite for system effectiveness.

Schade [29] distinguishes between acceptability and acceptance. The term acceptability refers to a prospective judgement regarding a system that has not yet been adopted or experienced. In contrast, acceptance includes a behavioural or reactive connotation and thus refers to systems already in use. Since most ARAS and OBIS are not yet implemented, the term 'acceptability' is used in the present paper in reference to assistive systems for PTWs.

A large range of models and constructs have been proposed to explain and predict user acceptability or the acceptance of technologies. The forecast of user acceptance, as early as possible in the design process, can be of great interest to the manufacturing industry, as there are large investments at stake. Among the most influential models proposed is the 'Technology Acceptance Model' [30] which mentions prospective user's overall attitude towards a given system as determinant of whether or not it will be used. Shackel's model [31] alternatively conceptualises system acceptability 
Table 1 Full list of assistive and informative systems included in MOPROQ-3 [28]

\begin{tabular}{|c|c|}
\hline System & Description \\
\hline Adaptive Cruise Control (ACC) & a system that adapts the distance to the vehicle ahead automatically \\
\hline advanced front-lighting system & $\begin{array}{l}\text { improves the headlamp illumination by means of continuous adaption of the headlamps } \\
\text { according to the driving situation }\end{array}$ \\
\hline ABS & $\begin{array}{l}\text { a system that prevents the wheels from locking especially when braking on wet or slippery } \\
\text { road surface }\end{array}$ \\
\hline airbag & $\begin{array}{l}\text { safety device that reduces the incidence and severity of injuries by absorbing the energy } \\
\text { of an impact }\end{array}$ \\
\hline blind spot monitor & a system that detects other vehicles located to the driver's side and rear \\
\hline collision warning system & a system that warns riders of any dangers that may lie ahead on the road \\
\hline combined braking systems & $\begin{array}{l}\text { application of one brake control will activate both front and rear brakes, for example, with } \\
\text { automatic brake force distribution }\end{array}$ \\
\hline curve speed warning system & $\begin{array}{l}\text { a system that warns the rider if he/she enters a curve at a speed that will not allow him/her to } \\
\text { drive through the curve safely }\end{array}$ \\
\hline emergency brake assistance & ensures maximum braking power in an emergency situation \\
\hline GPS & navigation \\
\hline ISA & $\begin{array}{l}\text { a system that monitors vehicle speed and local speed limit warns the driver and/or reduces speed } \\
\text { when the vehicle is detected to be exceeding the speed limit }\end{array}$ \\
\hline $\begin{array}{l}\text { in-vehicle emergency call system } \\
\text { (eCall) }\end{array}$ & $\begin{array}{l}\text { a system that sends for example GPS coordinates to local emergency agencies in order to bring } \\
\text { rapid assistance to drivers involved in a collision }\end{array}$ \\
\hline lane keeping assistant & a system that warns a driver when the vehicle begins to move out of its lane \\
\hline night vision & system to enhance night vision \\
\hline slipper clutch/back-torque limiter & $\begin{array}{l}\text { a specialised clutch to mitigate the effects of engine braking when riders decelerate as they enter } \\
\text { corners }\end{array}$ \\
\hline $\begin{array}{l}\text { Traction Control System (TCS) } \\
\text { tyre pressure control system } \\
\text { vacuum servo }\end{array}$ & $\begin{array}{l}\text { a system that intervenes and prevents the motorcycle from sliding on loose or slippery surfaces } \\
\text { a system that transmits the air pressure and/or temperature measured in the tires to a display } \\
\text { provides assistance to the rider by decreasing the braking effort }\end{array}$ \\
\hline
\end{tabular}

as a function of three orthogonal dimensions (utility, usability and likeability), which are balanced against cost or social consequences of using a system. Finally, Nielsen's model [32] conceptualises the overall acceptability of a system as a function of its social and practical acceptability.

Schlag's 'Heuristic model of individual acceptance' [33], which was further developed by Schade [29, 34-36], combines attributes from previous acceptability models and considers that key variables determining acceptance are structured on two levels. On the first level three distal predictors of acceptability are distinguished: problem awareness, general attitudes and social norms. 'Problem awareness' is a precondition for developing a positive attitude towards a proposed solution. 'General attitudes' refer to individual expectations about the consequences of the behaviour in question and their value for a person; the motives for riding motorcycles will influence the attitude towards a proposed solution. 'Social norms' refer to an individual's perception of opinions from significant others and the motivation to comply with them. These three variables constitute the individual background. They are the necessary but not sufficient precondition for acceptability and influence the proximal level variables, which relate to system characteristics and include 'perceived effectiveness' (individual advantage of a system) and 'perceived equity' (no comparative disadvantage to others) [36].

Schlag and Schade's heuristic model is more comprehensive than previous models, since it combines the most influential aspects of acceptance that have been identified by previous authors. The distinction between proximal and distal influences on acceptance also provides a useful framework for conceptualising the different influences on acceptability. A similar distinction between 'general indicators' (background variables, attitudes to driving behaviour and traffic safety, responsibility awareness, social norms etc.) and 'system-specific indicators' (perceived efficiency, effectiveness, usability and usefulness, affordability etc.) was recently been made by Vlassenroot et al. [37].

Understanding distinct influences on acceptability is crucial, since systems may vary along different dimensions. Arndt [38] proposed assessment criteria that determine ADAS acceptability for passenger cars. These include usability, safety benefits, driving pleasure, comfort, trust and environmental friendliness. According to Arndt, these variables are not necessarily correlated and can even produce opposing influences. For example, ISA is perceived as having high safety benefits, but also perceived as restricting the driving tasks and hence only considered suitable for novice drivers.

In summarising acceptability research, Regan et al. [39] propose the following key constructs which underlie most models of acceptability: usefulness (whether a system enhances task performance), ease of use (whether the use of a system is easy to learn and with small effort), effectiveness (whether a system works in accordance with its functional description; however a system can have high utility but low usability), affordability (the willingness and ability to buy a system) and social acceptability (broader social issues which influence the judgement of acceptability of a system). In the current paper, these key constructs were applied to the specific needs and concerns of PTW riders in order to better understand acceptability of PTW assistive systems.

\section{Methodology}

Based on the review of previous acceptability research, a series of qualitative focus group interviews were conducted with motorcycle riders throughout several European countries. The primary aim of the focus group interviews was to amass qualitative data about motorcyclists' attitudes and opinions regarding assistive systems. These qualitative results are informative in their own right but, more importantly, were subsequently used to develop a quantitative survey assessing riders' acceptability of 
assistive systems (see Section 3.2), which was then administered to a large sample of riders using a web-based platform (see Section 3.3).

\subsection{Focus group interviews: PTW riders' behaviour and attitudes}

3.1.1 Development and analysis procedure: Focus group interviews form an appropriate tool for gathering qualitative data about attitudinal and behavioural related variables, as well as motivation for riding, riding style, safety attitudes or risk behaviours, which could influence riders' acceptability of ARAS and OBIS. The gathered data provide a deeper understanding of the relationships between these variables and ITS acceptability [40-42]. This understanding subsequently formed the basis for the design of targeted questions within the MOPROQ-3 tool to enhance questionnaire validity concerning the requested output, that is, rider acceptability of assistive and informative systems.

Two sets of focus groups were conducted. The first set aimed at gathering detailed information about PTW riders' attitudes towards motorcycle riding. This included motivations for riding a PTW, different riding styles, safety attitudes or risk awareness, but also rider attitudes towards ARAS and OBIS. Rider focus groups were conducted in autumn 2010 in nine European countries (Austria, Czech Republic, Finland, France, Germany, Greece, Italy, Portugal and Spain). These provided a first insight into the relationship between motivational and behavioural characteristics of PTW riders. Results from the first set of focus group discussions were used to develop guidelines for the second set of focus groups, the objective of which was to understand how aspects of rider behaviour and motivations are related to ARAS and OBIS acceptability.

The second set involved three focus group discussions conducted between February and April 2011 in Germany and Austria. Examples of opening questions were

Which assistive technologies for motorcycles do you know?

Which of the systems would you like to use? Do you already have experience with using such a system?

When exactly do you need the support of the system (in everyday situations)?

These focus group discussions focused mainly on ABS, traction control systems (TCS) and lighting systems. These systems were selected because they are commercially available for PTWs, so riders may have already had experiences with the systems in question. ISA was also discussed because considerable research [43] has suggested its safety benefits for passenger car drivers and it is therefore considered as a system with high potential for improving PTW riders' safety. Participants were asked whether their motorcycles have been retroactively fitted with ABS and/or TCS. They were also asked about the advantages and disadvantages of ABS, TCS, daytime running lights (DRLs) and T-lighting and to suggest potential improvements that might increase the acceptability of each system.

Further aspects of the discussion were the reliability of ABS and TCS and riders' sources of information about assistive technologies (i.e. when purchasing a new motorcycle). The riders were asked whether they would accept ISA systems; and about the perceived advantages and disadvantages and design issues for PTW-specific ISA (e.g. preferred human-machine-interface alert style: visual, auditory and tactile). Other questions were asked about systems that are not yet on the market or are relatively uncommon including adaptive front lighting/active headlights, airbags, following distance warning, curve speed warning, lane departure warning, lane keeping systems, vehicle-to-vehicle (V2V) communications and collision warnings.

The focus group interviews were analysed following the content analysis of Mayring [41], which is a four-stage procedure to categorise qualitative data,

1. first step ('Paraphrasing'): the statements of the participants are shortened and the language is adequately standardised. The product of this procedure is a list of topics, which can be classified and summarised;

2. second step ('Generalisation'): all topics have to be on a predefined level of abstraction, this level of abstraction must be consistent;

3. third step ('First reduction'): all equivalent paraphrases will be removed, only the essential paraphrases remain in the text;

4. fourth step ('Second reduction'): all similar paraphrases are summarised, and if necessary the classification will be adapted.

3.1.2 Results: The main categories, which resulted from the first level of analysis, were: riding behaviour, safety attitudes and perceived risk variables. Further, the level of knowledge about various ITS technologies among the participants and the potential advantages and disadvantages of specific systems were discussed. In the following these main categories are described in more detail.

Attitudinal variables: Participants perceived limitations concerning the usability and reliability of assistive systems, in relation to system safety. Some riders expressed concerns regarding their safety if the system failed to work, because riders might not know how to respond appropriately in such a situation.

The group discussion results clearly showed that the perception of safety while riding a PTW is primarily not linked to technology, but rather to the behaviour of other road users, especially the perceived erratic behaviour of passenger car drivers. Additionally, maintenance of the PTW itself (e.g. tyres) is considered more important for safety than the use of assistive systems. Wearing protective clothing is also considered as part of riding safety, although the riders stated that wearing protective clothing is influenced by variables such as the aim of the trip, trip length or weather conditions.

Behaviour related variables: In terms of riding behaviour, focus group participants noted some barriers to the uptake of specific systems. The general perception was that developing an anticipatory riding behaviour is one of the most important aspects for riding safety. Riding experience was considered as a key issue for developing a safe riding behaviour. Riders therefore argued that the use of assistive systems may retard the development of riding skills and that equivalent (or superior) safety measures could be achieved by improving rider training.

In terms of risk-taking behaviour, riders' perceptions of their own risky or illegal behaviour were linked to aspects of comfort and safety by some participants. For example, crossing the solid line or using restricted lanes (e.g. bus 
lanes in certain countries) are considered as safer strategies than obeying traffic rules in certain situations. Furthermore, assessment of whether a specific riding behaviour should be considered 'safe' or 'critical' varies between riders.

Level of knowledge concerning ITS technologies: The focus group participants generally had good knowledge of assistive systems, which was typically based on experiences while driving passenger cars equipped with assistive systems. Various ITS technologies were mentioned and discussed during the group discussions, including ABS, brake booster, TCS, ISA, tyre pressure control system, collision warning systems, GPS navigation, night vision and vision enhancing systems, V2V communications, etc. In general riders' attitudes towards ARAS and OBIS for PTWs were rather negative, with some exceptions; ABS was an example of an assistive system that generated positive attitudes. The dominant view was that systems should only intervene if the rider is unable to react appropriately and in time, in emergency situations and should only operate 'in the background'. The participants further expressed that they would like to decide on their own whether to use or to switch off an equipped technology.

Based on the focus group discussions together with the current state of the art, relevant variables that appear to influence riders' acceptability of ITS were derived in order to develop an appropriate tool for assessing acceptability. These variables concern: (a) riders' behaviour and attitudes towards riding and safety; (b) sub-populations of PTW riders based on frequency and type of riding [44] and (c) personality traits of PTW riders [45]. These three categories all represent facets of the individual that may predict a general tendency to accept assistive systems. In addition to the individual differences aspects that were explored, both the focus groups and the literature review highlighted the importance of surveying attitudes on a range of assistive systems, since within the focus groups attitudes varied for specific systems (e.g. ABS attitudes were relatively positive, compared with ISA attitudes which were extremely negative).

\subsection{Motorcyclists' profiling questionnaire}

Within the 2-BE-SAFE project a three-part survey named the MOPROQ was designed. Each section of MOPROQ was designed for a distinct purpose: to identify subpopulations of riders based on sociodemographic variables, motivation and riding behaviours (MOPROQ-1); to assess riders' personality traits and safety attitudes (MOPROQ-2); and to assess acceptability of assistive systems (MOPROQ-3). The current paper describes the development of MOPROQ-3 only; MOPROQ-1 and MOPROQ-2 were developed in earlier studies based on previous, related surveys.

\subsubsection{Motorcyclists' profiling questionnaire-1:} MOPROQ-1 specifically addressed the question how subpopulations of PTW riders can be distinguished. There is no consistent typology of subpopulations of motorcyclists in literature, but various studies show that subpopulations are defined based on specific aspects, such as risk awareness [44, 46]. MOPROQ-1 focused on sub-populations of PTW riders (e.g. commuters, sports riders) using several variables including: motivations for using PTWs, riding practices and crash history. Items recorded socio-demographic data (19 items), motivations for riding (15 items), general motorcycling practices (6 items), risky manoeuvres when riding (10 items), attitudes towards speed (6 items) and accident history (16 items).

\subsubsection{Motorcyclists' profiling questionnaire-2:}

MOPROQ-2 [47] was based on previous questionnaires $[45,48]$ that explored the relationship between personality traits and characteristics, and attitudes towards traffic safety and risky riding behaviours. The aim of MOPROQ-2 was to explore differences between subpopulations of riders, both within and between different countries. Items assessed aspects including personality (anxiety, anger, sensation seeking, altruism and normlessness), safety attitudes (traffic flow, rule obedience, speeding and fun riding) and risky behaviours (risky riding behaviours, speeding, self-assertiveness and rule violations).

3.2.3 Motorcyclists' profiling questionnaire-3: The focus group results formed the basis for MOPROQ-3, which was designed to extend previous research [38] by developing a questionnaire that assessed riders' acceptability of assistive and informative systems. The focus group discussions particularly informed the development of riding scenarios, which were prototypical critical situations in which PTW assistive systems might be helpful, as well as to develop the list of specific assistive and informative systems that were included in the survey (see Table 1). In addition, the focus group results were used to create statements for measuring acceptability, which related specifically to the perceived advantages, perceived disadvantages and potential improvements of various systems.

The first step in designing the survey was to select the systems that would be explored in detail through MOPROQ-3. The selection was based on PTW risk factors as identified through in-depth crash analysis [16], the needs and concerns of PTW riders expressed within the focus groups, commonly-encountered riding situations and the current state of the art in PTW ITS. When combined, these elements resulted in the selection of four systems: braking enhancing systems, TCS, distance keeping and navigation systems.

These systems were selected because they were already commercially available for PTWs at that time, hence riders may have already had experiences with these. ISA was also discussed because considerable research [43] has suggested its safety benefits for passenger car drivers and it is therefore considered as a system with high potential for improving PTW riders' safety. Riding scenarios were designed to describe specific situations through which system operation would be clear. Under these scenarios rider acceptability of specific ARAS and OBIS is addressed. Focus group interviews results indicated that riders' attitudes towards assistive systems are quite negative and that riders express in-principle objections to the use of technology that interferes with vehicle operations. Therefore a requisite condition for each scenario was that it demonstrates the potential applicability and value of the system in context (see Fig. 1). The first two situations, in which stability and braking enhancing systems could be useful, were chosen because these systems are relevant for nearly all of the loss-of-control incidents. Such incidents could occur because of environmental hazards, such as wet roads or loose covering on the road. The MAIDS study shows that almost $8 \%$ of all accidents are related to such environmental hazards [16]. In addition, within the focus group discussions it emerged that riders perceive road surface conditions as a major concern, as poor maintenance, loose grit or dirt can make riding hazardous. In order to mitigate the consequences of the most frequent human 


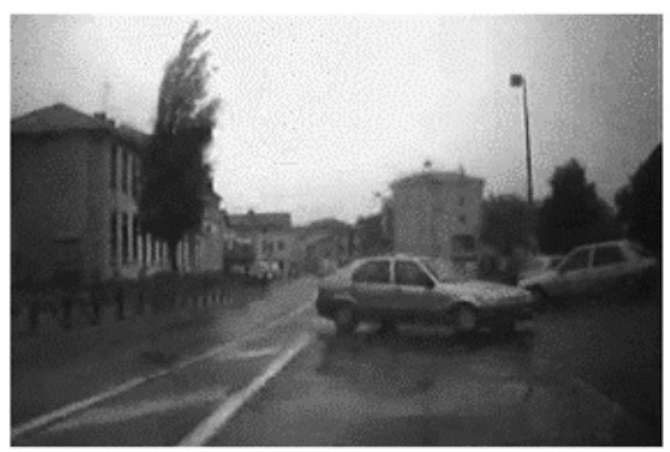

$a$

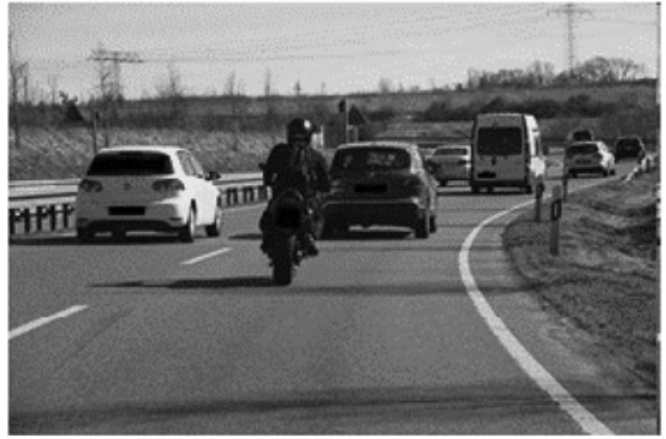

c

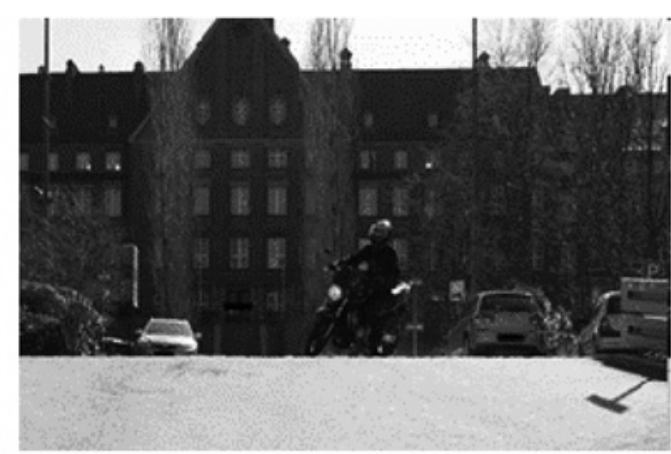

b

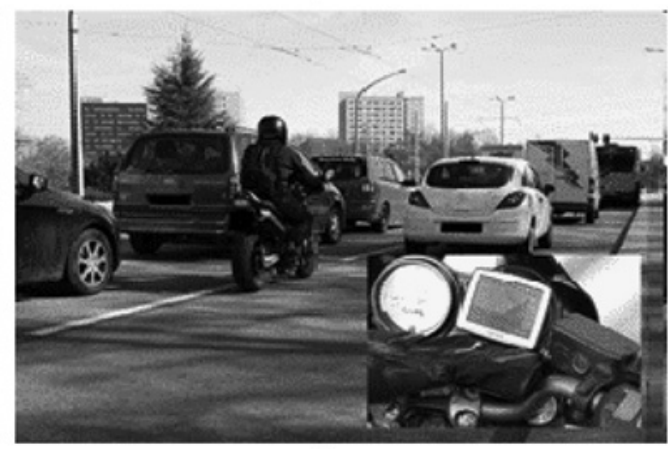

d

Fig. 1 Emergency scenarios in MOPROQ 3

$a$ Braking Enhancing Systems

'You are riding on your motorcycle on this wet road. Suddenly the oncoming vehicle turns in and you need to brake immediately. A system on your motorcycle intervenes during braking and prevents the wheels from locking and the bike sliding. The system is available operating either on both wheels, or on the front or rear wheel, and might be equipped with an automatic brake force distribution

$b$ Traction Control Systems

'You are riding on a winding road, parts of the road surface has loose covering. The motorcycle runs the risk of sliding. Your bike is fitted with a system that intervenes and prevents the motorcycle from sliding on loose (or slippery) surfaces. When a wheel spin is detected the engine output is controlled to allow grip to be regained. Such a system can accommodate the speed, lean angle and/or operating mode (sport/race/rain etc.)'

$c$ Distance Keeping

'You are riding on a busy motorway. Following distance to the other road users has to be adapted constantly. A system adapts the distance to the vehicle ahead automatically, either by slowing the bike if following too closely, or accelerating the bike to maintain a preset following distance when traffic allows. (The system might also provide a warning if the rider runs the risk of colliding with another vehicle and provides brake support. Furthermore it might provide lane keeping maintenance.)'

$d$ Navigation

'You are riding in a foreign city during rush hour riding to your hotel. The reception will close in the next 15 min. Thus, you have to react quickly and decide immediately how to go there. A system helps you to find your destination and guides you through the city traffic via visual and/or acoustic information'

error, failure to detect a PTW rider in time [16] the third situation was created for the use of crash avoidance systems (e.g. autonomous cruise control, lane keeping assistance). Focus group participants emphasised that critical situations for riders often arise from erratic behaviour of car drivers, such as car drivers cutting into the rider's lane. The fourth situation was supposed to give information about the acceptance of informative systems (e.g. GPS).

The next step was to define key variables and items for measuring riders' acceptability towards the systems considering the aforementioned scenarios. In particular, appropriately selected indicators were defined to elicit riders' opinions regarding the acceptability of each system. These were: usefulness, effectiveness, affordability and social acceptability [3]. For each indicator, specific questions were formulated. In particular, two types of questions were designed: general questions that applied to all systems; and system-specific questions concerning operational characteristics unique to that system. A 5-point Likert scale, ranging from 'I agree totally' to 'I do not agree at all', was constructed for participants to rate their level of agreement with each statement. Several questions were designed taking into account results of the focus group interviews concerning the advantages and disadvantages of the systems, riders' concerns on system operation, as well as potential additional improvements. In addition, standard affordability/willingness-to-pay items were also included in the questionnaire to provide a direct measure of rider acceptability. These were: 'I would like to have such a system on my motorcycle' using a 5-point Likert scale and 'I would pay an additional fee to have such a system fitted on my motorcycle' where the respondent had to state the amount he/she would be willing to pay.

The items were designed to assess the level of importance for each key variable are demonstrated (see Table 2).

To cater for riders' concerns and negative acceptability that became evident through the focus group interviews, which was mainly a result of the intervening nature of system operation, a different set of questions was designed. The aim was to explore rider preferences towards the degree of system intervention, as well as system-specific improvements. The formulated questions were either general and applied to all systems or system-specific questions relevant to the unique the system operation (Table 3).

Lastly, rider indicators of acceptability considering several other systems (Table 1) that have the potential to address specific riding related risky situations, as these have been highlighted by road safety research, were investigated in a 
Table 2 Key variables and items for measuring riders' acceptability

usefulness (the degree to which a person believes that using a particular system will enhance his/her performance)

general questions (first applying to all systems, second to all systems except for the navigation system)

braking enhancement systems (system-specific questions)

TCS (system-specific questions)

distance keeping systems (system-specific questions)

navigation (system-specific questions)
- such a system would support the riding task

- such a system would be helpful for less experienced riders

- such a system would contribute to better stability of the motorcycle when braking

- such a system would increase braking distance

- such a system would be effective on curves

- such a system would contribute to a better stability of the motorcycle

- such a system would hinder me from overtaking in a safe way as I cannot accelerate appropriately

- such a system intervenes too much in the engine's performance

- such a system would make it more easy to concentrate on the surrounding traffic

- such a system would be helpful in unclear situations

- such a system distracts the rider from the surrounding traffic

- such a system might cause unclear situations (e.g. in case the

system temporarily does not get traffic information)

effectiveness (the system must do what it is designed to do, that is, it must have utility)

general questions (1st applying to all systems except for the navigation system, 2nd applying to all systems)

affordability (willingness to pay) general questions (applying to all systems)
- such a system would prevent critical situations

- such a system would prevent traffic accidents

- I would like to have such a system on my motorcycle

- I would pay an additional fee to have such system fitted to my motorcycle

social acceptability (global aspect of acceptability, including concerns etc.)

general questions (applying to all systems, except for the navigation system)

braking enhancement systems \& TCS (system-specific questions)

traction control systems (system-specific questions)

distance keeping systems (system-specific questions)
- such a system may lead to riskier riding behaviour

- such a system would lead to dangerous situations when braking

- such a system is patronising the rider

- such a system reduces the fun of riding a motorcycle

- such a system takes the personal responsibility away less detailed manner. Survey participants were asked to indicate how important each system was on a 5-point Likert scale ranging from 'important' to 'not important'. A sixth option, 'I do not know the system', is included to assess respondents' level of familiarity with PTW assistive systems. The aim of this is to provide insight about rider preferences concerning a wide variety of ITS systems. Systems that are rated high by riders could be explored in depth in future studies, while the reasons behind systems that score low should be determined and possible supportive actions should be designed.

\subsection{Survey administration and summary results}

In terms of survey distribution, all three parts of MOPROQ were administered as a single online survey, which was available online from the end of April 2011 until the end of May 2011. Recruitment notes were distributed to motorcycle associations in Austria, the Czech Republic, Great Britain, Finland, France, Germany, Greece and Portugal. Altogether 6297 questionnaires were completed in seven different languages (Czech, English, Finnish, French, German, Greek and Portuguese).

Table 3 Items for measuring riders' preferences concerning ITS operation

general questions (applying to all systems, except for the navigation system)

braking enhancement systems and TCS (system-specific questions)

distance keeping (system-specific questions)

navigation (system-specific questions)
- it should be possible to switch the system off

- it should be possible to adjust settings for my needs

- the system should provide a warning only and should not reduce engine power

- the system should not intervene when the bike is on a slope

- it should be possible to switch the system off

- the weight of the system should not influence the riding task

- the system should include emergency braking assistance

- it should be possible to adjust the parameters used by the system for my needs (e.g. safety distance)

- the information about traffic, construction sites etc. should be up-to-date

- the display should be of an adequate size

- the visual information should be projected onto the visor of the helmet

- the system should dispose of a speech input

- the given acoustic information (volume) should adjust to surrounding sounds 
Beanland et al. [49] provide a detailed description of the survey sample and results. The following sections provide a summary of the main indicators for acceptability which have been identified using the MOPROQ tool.

\subsubsection{Acceptability indicators: Risk as downside of} riding: Riders who showed higher acceptability of ARAS and OBIS were more likely to nominate 'risk' as the greatest downside to riding, as they perceived potential benefits of assistive systems for improving their on-road safety.

Fear and anxiety: Fearing the worst, worrying about things and getting upset easily were personality traits that showed a moderate association with acceptability. Riders with higher acceptability of assistive systems reported higher levels of fear.

Speed: Acceptability was associated with several statements regarding riding speed. Riders who showed lower acceptability cluster were less likely to agree to the following statements: 'if you are a safe rider, it is acceptable to exceed the speed limit by $10 \mathrm{~km} / \mathrm{h}$ ', 'exceed the speed limit on rural roads (more than $10 \mathrm{~km} / \mathrm{h}$ )' and 'overtaking the car in front when it is driving at the speed limit'.

Fun and excitement: Variables related to motivations for riding which were associated with acceptability were 'I have a need for fun and excitement in traffic' and 'riding is more than transportation, it is also speeding and fun'. Riders who reported higher acceptance of ARAS and OBIS more often reported to have a need for fun and excitement.

Interference with riding task: The analysis showed that riders' acceptability towards informative systems (e.g. GPS and night vision) was higher than towards assistive systems that intervene with the riding task (e.g. ISA and ACC).

Usefulness: Systems that were perceived as more useful in emergencies (e.g. ABS, EBA or eCall, a device that will automatically dial 112 in the event of a serious road accident) were rated as more important for riding safety than ACC or ISA.

\subsubsection{Barriers to acceptability: Within the MOPROQ} tool several open-ended questions were included, in order to give the respondents the possibility to provide their point of view on assistive systems. The following concerns were stated by the respondents regarding the use of ARAS and OBIS:

Training and teaching of riding skills: A strong majority of the respondents, particularly the more experienced riders, stressed the importance of the provision of more comprehensive and regular rider training, instead of developing new assistive systems in order to improve PTW rider safety. Concerns were raised that assistive systems may even impede rider training, because riders might over-rely on the system and consequently will never learn or will even lose - the technical riding abilities that support them to avoid and/or resolve critical situations. In their opinion this especially applies to novice riders and riders who have not ridden a motorcycle for a longer period of time. However the assumptions about the effectiveness of motorcycle rider training are not based on objective evidence.

Vehicle control: A strong reluctant attitude towards systems which actively interfere in the riding task and remove the responsibility of the rider to control the PTW was observed (e.g. ISA, ACC and lane keeping assistance). This attitude depicts a main barrier because the perceived usability and satisfaction are low. This has negative implications for the system reliability: if riders fear that a system might fail and not be reliable, they will be unwilling to pay extra money for it. These views might be critically questioned as many motorcycle riders do not have direct experience with assistive systems (most of them are not yet commercially available). However, both the current study and earlier studies [50] highlight the importance of such arguments and they must therefore be carefully considered in order to reach acceptance. More effort should be put on the understanding of training and skill acquisition and in the identification of systems which can offer the best benefit for PTW riders.

Technical maturity and reliability: Even though some of the systems are perceived as potentially beneficial, such as ABS, emergency brake assistance or traction control, riders stated concerns regarding the technical maturity and reliability of the system. The consequence is a lower willingness to accept certain systems.

Cost argument and applicability: Many respondents fear additional costs in connection with assistive systems, especially technically sophisticated ones. Riders anticipate that assistive systems will either increase the price of the motorcycles (especially of small scooters and mopeds) or that there would be an optional retrofitting of systems, which incurs high costs relative to the overall cost of PTWs. In addition, it is considered impractical to fit assistive systems on PTWs retroactively. It should be taken into account, that cost is anticipated to be a significant parameter, as PTW cost - and one of the motives for its use - is considerably lower to that of passenger cars.

Motivation of industry: Many motorcycle riders were critical towards industry motivations. They doubted that manufacturers have genuine safety concerns for riders in mind when developing assistive technology, focusing rather on their potential company profit.

Behaviour of other road users: Respondents expressed that many of the dangers that PTW riders face derive from erroneous behaviour of other road users. They criticised that too much focus is put on the development of assistive systems controlling PTW movement as a means of improving PTW rider safety, instead of focusing on interaction, awareness and understanding between different road user groups. In particular, participants questioned the safety benefit of assistive systems that focuses solely on the PTW riders (and associated restrictions for motorcycle riders) without considering the behaviour of other traffic participants.

\section{Discussion}

This paper presents the methodological development of MOPROQ-3, a specific tool for assessing motorcyclists' acceptability of ITS, as part of the broader MOPROQ study. The methodological procedure of the MOPROQ tool is aligned to attain in-depth data on perceptions of risk and safety, personality traits, riders' motivations, behaviour and attitudes. The first two parts of the three-part survey, MOPROQ-1 and MOPROQ-2, were developed in earlier studies based on previous, related surveys. MOPROQ-3 was designed to extend previous research [38] by developing a questionnaire that assessed riders' acceptability of assistive and informative systems. Thus the third part of the questionnaire, MOPROQ-3, can be considered as a validated tool to assess acceptability of a diverse range of assistive systems among a large sample of riders, which is 
an essential enhancement concerning representativeness and generalisability of conclusions.

The main result of the analysis of the data gathered by applying the MOPROQ-3 questionnaire was that PTW riders have a rather low acceptability of PTW assistive systems when compared with the acceptance of similar systems in passenger cars. This is probably because of substantial differences between the riding and the driving tasks, which concerns motivations for riding, as well as physical differences between PTWs and passenger cars. These differences influence the practicality, effectiveness and affordability of assistive systems for PTWs compared with passenger cars. The qualitative data gathered within the MOPROQ-3 development process suggest there is large potential to increase acceptance, either through changing the riders' attitudes towards the technology or by changing the technology itself. PTW riders estimate the effects of measures enhancing riding skills and rider training (especially for risky riding situations such as slippery roads, surfaces, curves, visibility conditions etc.) as more suitable for motorcyclists' safety, especially for novice riders, than assistive systems. Systematic promotion and teaching of skills to understand the specific condition and behaviour of other road user groups can provide significant improvements in this regard. In order to avoid uncertainty and potential communication breakdowns between road users, another focus has to lie on enhancing interaction and communication skills in traffic.

Further development of the MOPROQ tool is worthwhile. Future research should attempt to fine tune the differentiation between subpopulations of PTW riders concerning acceptability of ITS. It would also be valuable to administer the survey to a range of samples, both within Europe (which formed the bulk of the initial validation sample) and throughout other countries. In the present study, commuters were underrepresented among the survey participants, whereas recreational riders were overrepresented. It is therefore of great importance to gather additional data about the influencing variables on acceptability of ITS technology among other subpopulations of riders, including everyday riders who use their PTWs for commuting and other daily activities. Low-threshold distribution channels therefore should be selected in order to make the survey easily accessible.

\section{Acknowledgments}

This paper was elaborated within the project 2-BE-SAFE commissioned by the Seventh Framework Programme of the EC. Financial support for the Australian involvement was provided through a National Health and Medical Research Council-European Union Health Collaborative Research Grant (grant no. 490992). We would like to thank all contributing authors of the deliverable, the Project's Scientific Leader, Stéphane Espié and the Project Coordinator, Stéphane Laporte.

\section{References}

1 European Commission-Press release: Improved safety for motorcycles: European Commission welcomes Council approval, Brussels, 2012, http://europa.eu/rapid/press-release_IP-12-1348_en.htm, December 2013

2 Spyropoulou, I., Yannis, G., Winkelbauer, M., Golias, J.: 'Powered Two Wheelers safety measures: recommendations and priorities'. Proc. of the 12th WCTR Conf., Portugal, Lisbon, 2010

3 Regan, M., Triggs, T., Young, K., et al.: 'On-road evaluation of intelligent speed adaptation, following distance warning and seat belt reminder systems'. Final Results of the Australian TAC Safecar Project, Report No. 253, Monash University Accident Research Centre, Australia, Melbourne, 2006

4 Spyropoulou, I., Golias, J., Karlaftis, M., Penttinen, M., Vaa, T.: 'ITS Solutions and accident risks: Prospective and limitations', Transp. Rev., 2008, 28, (5), pp. 549-572

5 Rakotonirainy, A., Haworth, N.: 'Institutional challenges to ITS deployment and adoption'. 29th Australasian Transport Research Forum, Australia, Gold Coast, September 2006

6 Van de Laan, J., Adriaan, H., de Ward, D.: 'A simple procedure for the assessment of acceptance of advanced transport telematics', Transp. Res. C: Emerg. Technol., 1997, 5, (1), pp. 1-10

7 Brenac, T., Clabaux, N., Perrin, C., et al.: 'Motorcyclist conspicuityrelated accidents in urban areas: A speed problem?', Adv. Transp. Stud., 2006, 8, pp. 23-29

8 Nordqvist, M., Gregersen, N.: 'Study on motorcyclist's behaviour and attitude towards road safety 2010' (SMC, Borlänge, Sweden, 2011)

9 Simpkin, B., Lai, F., Chorlton, K., Fowkes, M.: 'ISA-UK, Intelligent Speed Adaptation. Results of motorcycle trial' (University of Leeds, Leeds, UK, 2007)

10 Biral, F., Lot, R., Rota, S., et al.: 'Intersection support system for powered two-wheeled vehicles: Threat assessment based on a receding horizon approach', IEEE Trans. Intell. Transp. Syst., 2012, 13, (2), pp. $805-816$

11 Huth, V., Biral, F., Martin, O., et al.: 'Comparison of two warning concepts of an intelligent Curve Warning system for motorcyclists in a simulator study', Accident Anal. Prevention, 2012, 44, (1), pp. 118-125

12 Marumo, Y., Katagiri, N.: 'Control effects of steer-by-wire system for motorcycles on lane-keeping performance', Veh. Syst. Dyn.: Int. J. Veh. Mech. Mobility, 2011, 49, (8), pp. 1283-1298

13 Valtolina, S., Vanzi, S., Montanari, R., Minin, L., Marzani, S.: 'Design of warning delivery strategies in advanced rider assistance systems'. ASME 2011 World Conf. on Innovative Virtual Reality, Italy, Milan, June 2011, pp. 41-50

14 Giovannini, F., Savino, G., Pierini, M., Baldanzini, N.: 'Analysis of the minimum swerving distance for the development of a motorcycle autonomous braking system', Accident Anal. Prev., 2013, 59, pp. $170-184$

15 Savino, G., Giovannini, F., Baldanzini, N., Pierini, M., Rizzi, M. 'Assessing the potential benefits of the motorcycle autonomous emergency braking using detailed crash reconstructions', Traffic Injury Prev., 2013, 14, pp. 40-49

16 ACEM (Association des Constructeurs Européens de Motocycles): 'In-depth investigations of accidents involving powered two-wheelers (MAIDS)' (Brussels, Belgium, 2009), pp. 1-179

17 Elliot, M., Baughan, J., Broughton, C., et al.: 'Motorcycle safety: a scoping study' Prepared for Road Safety Division, Department for Transport'. TRL Report TRL581, 2003

18 Rizzi, M., Strandroth, J., Tingvall, C., et al:: 'The effectiveness of antilock brake systems on motorcycles in reducing real-life crashes and injuries', Traffic Injury Prev., 2009, 10, pp. 479-487

19 Savino, G., Pierini, M., Rizzi, M., Frampton, R.: 'Evaluation of an autonomous braking system in real-world PTW crashes', Traffic Injury Prev., 2013, 14, (5), pp. 532-543

20 ETSC (European Transport Safety Council): 'Vulnerable riders: Implications of motorcycling in the European Union' (ETSC, Brussels, Belgium, 2008), http://www.etsc.eu/documents/ ETSC_Vulnerable_riders.pdf, December 2013

21 Haworth, N.L., Rowden, P.J.: 'Challenges in improving the safety of learner motorcyclists'. Proc. 20th Canadian Multidisciplinary Road Safety Conf., Ontario, Niagara Falls, June 2010

22 Nilsson, G.: 'The effects of speed limits on traffic accidents in Sweden'. Proc. of Int. Symp. on the Effects of Speed Limits on Traffic Accidents and Transport Energy use, Ireland, Dublin, October 1982, pp. 1-8

23 Aarts, L., van Schage, I.: 'Driving speed and the risk of road crashes: A review', Accident Anal. Prev., 2006, 38, (2), pp. 215-224

24 Cook, S., Frampton, R., Grant, R., et al.: 'Powered two wheeler Integrated Safety (PISa): Review of current PTW accident data' Vehicle Safety Research Centre, Loughborough University, D2, 2007

25 Hughes, P., Cole, B.: 'What attracts attention when driving?', Ergonomics, 1986, 29, (3), pp. 377-391

26 Doğan, A., et al.: 'Evaluation of intersection collision warning system using an inter-vehicle communication simulator'. Proc. of the Seventh Int. IEEE Conf. on Intelligent Transport Systems, Washington, USA, 2004, pp. 1103-1108

27 Beanland, V., Lenné, M., Underwood, G.: 'Safety in numbers: Target prevalence affects detection of vehicles during simulated driving', Attention, Percept., Psychophys., 2014, 76, (3), pp. 805-813 


\section{www.ietdl.org}

28 Lenné, M., Beanland, V., Füssl, E., et al.: 'Relationships between rider profiles and acceptance of Advanced Rider Assistance Systems', 2 BESAFE Project Deliv. 9 Work Package, 2011, 3.3, pp. 91-96

29 Schade, J.: 'Individuelle Akzeptanz von Straßenbenutzungsentgelten', in Schlag B. (Ed.): 'Empirische Verkehrspsychologie' (Pabst Science Publishers, Lengerich, 1999), pp. 227-244

30 Davis, F.: 'Perceived usefulness, perceived ease of use, and user acceptance of information technology', MIS Q., 1989, 13, pp. 319-340

31 Morris, M., Turner, J.: 'Assessing users' subjective quality of experience with the world wide web: An exploratory examination of temporal changes in technology acceptance', Int. J. Hum.-Comput. Stud., 2001, 54, pp. 877-901

32 Nielsen, J.: 'Usability Engineering' (Academic Press, Inc., San Diego, CA, 1993)

33 Schlag, B., et al.: 'Public acceptability of transport pricing', IATTS Res., 1997, 21, (2), pp. 134-142

34 Schade, J., Schlag, B.: 'Acceptability of urban transport pricing'. VATT Research Report 72, VATT, Helsinki, Finland, 2000

35 Schade, J.: 'European research results on transport pricing acceptability', in Schade, J., Schlag, B. (Eds.): 'Acceptability of transport pricing strategies' (Elsevier, Oxford, UK, 2003), pp. 109-123

36 Schade, J., Schlag, B.: 'Kognitive Bedingungen der öffentlichen Akzeptanz von Straßenbenutzungsgebühren', Umweltpsychologie, 2004, 8, (1), pp. 210-224

37 Vlassenroot, S., Brookhuis, K., Marchau, V., Witlox, F.: 'Towards defining a unified concept for the acceptability of Intelligent Transport Systems (ITS): A conceptual analysis based on the case of Intelligent Speed Adaptation (ISA)', Transp. Res. F: Traffic Psychol. Behav., 2010, 13, (3), pp. 164-178

38 Arndt, S.: 'Evaluierung der Akzeptanz von Fahrerassistenzsystemen Prüfung eines Modells zur Vorhersage des Kaufverhaltens von Endkunden' (University of Technology, Dresden, Germany, 2010)

39 Regan, M., Mitsopoulus, E., Haworth, N., Young, K.: 'Acceptability of in-vehicle intelligent transport systems to Victorian car drivers'. RACV
Public Policy, Report No 02/02, Monash University Accident Research Centre, Melbourne, Australia, 2002

40 Mayerhofer, W.: 'Das Fokusgruppeninterview', in Buber, R., Holzmüller, H. (Eds.): 'Qualitative Marktforschung. Konzepte. Methoden. Analysen' (Gabler, S., Wiesbaden, 2007), pp. 479-488

41 Mayring, P.: 'Qualitative Inhaltsanalyse: Grundlagen und Techniken' (Beltz, 2003), pp. 1-135

42 Webb, C., Keverin, J.: 'Focus groups as a research method: a critique of some aspects of their use in nursing research', J. Adv. Nurs., 2011, 33, (6), pp. 798-805

43 Bayly, M., Regan, M., Hosking, S.: 'Intelligent transport systems and motorcycle safety'. Report No. 260, Monash University Accident Research Centre, Melbourne, Australia, 2006, pp. 1-76

44 Joshi, S., Bellet, T., Banet, A., et al.: 'Understanding risk taking behaviour within the context of PTW riders: A report on rider diversity with regard to attitudes, perceptions and behavioural choices', 2 BESAFE Proj. Deliv. 7 Work Package, 2011, 3, pp. 27-28

45 Chen, C.: 'Personality, safety attitudes and risky driving behaviours Evidence from young Taiwanese motorcyclists', Accident Anal. Prev. 2009, 41, pp. 963-968

46 Wong, J., Chung, Y., Huang, S.: 'Determinants behind young motorcyclists' risky riding behaviour', Accident Anal. Prev., 2010, 42, (1), pp. 275-281

47 Bellet, T., Banet, A., Paris, J., et al.: 'Motorcyclists' Risk Awareness' (2 BE SAFE User Forum, Paris, France, 2011)

48 Ulleberg, P., Rundmo, T.: 'Personality, attitudes and risk perception as predictors of risky driving behaviour among young drivers', Safety Sci., 2003, 41, pp. 427-443

49 Beanland, V., Lenné, M., Füssl, E., et al.: 'Acceptability of rider assistive systems for powered two-wheelers', Transp. Res. F: Traffic Psychol. Behav., 2013, 19, pp. 63-76

50 Cairney, P., Ritzinger, A.: 'Industry and rider views of ITS for safe motorcycling'. 23rd ARRB Conf. - Research Partnering with Practitioners, Adelaide, Australia, 2006 